\title{
Association between ACE2/ACE balance and pneumocyte apoptosis in a porcine model of acute pulmonary thromboembolism with cardiac arrest
}

\author{
HONG-LI XIAO ${ }^{1}$, LIAN-XING ZHAO $^{2}$, JUN YANG $^{2}$, NAN TONG $^{2}$, LE AN $^{2}$, \\ QI-TONG LIU ${ }^{3}$, MIAO-RONG XIE ${ }^{1}$ and CHUN-SHENG LI ${ }^{1}$ \\ ${ }^{1}$ Department of Emergency Medicine, Beijing Friendship Hospital, Capital Medical University, Beijing 100050; \\ ${ }^{2}$ Beijing Key Laboratory of Cardiopulmonary Cerebral Resuscitation; ${ }^{3}$ Department of Radiology, \\ Beijing Chao-Yang Hospital, Capital Medical University, Beijing 100020, P.R. China
}

Received May 20, 2017; Accepted September 1, 2017

DOI: $10.3892 / \mathrm{mmr} .2018 .8426$

\begin{abstract}
Acute pulmonary embolism (APE) is frequently reported in patients with cardiac arrest (CA) in emergency care. Pneumocyte apoptosis is commonly observed in the lungs following an APE. An important pathological mechanism evoking apoptosis during a lipopolysaccharide-induced acute lung injury is the angiotensin-converting enzyme 2 (ACE2)/ACE imbalance. The present study uses a porcine model to examine the anti-apoptotic effects of captopril on APE-CA and the return of spontaneous circulation (ROSC). Pigs were randomly assigned into four groups: Control, APE-CA, ROSC-saline, and ROSC-captopril. Surviving pigs were euthanized at $6 \mathrm{~h}$ and lungs were isolated for analysis using several biochemical assays. Compared with the control group, the ACE2/ACE ratio was lower in the APE-CA and ROSC pigs. In addition, APE-CA pigs had higher Bcl-2-associated X protein (Bax) and cleaved caspase-3 levels, and lower B-cell lymphoma-2 (Bcl-2) level compared to control pigs. Captopril treatment reduced lung apoptosis, as demonstrated by lower TUNEL-positive cells, higher Bcl-2, and lower cleaved caspase-3 protein levels in the lung. Notably, the ACE2/ACE ratio was positively correlated with Bcl-2 protein levels and Bcl-2/Bax ratio. In conclusion, captopril has a protective effect against lung apoptosis following ROSC and that maintaining the balance
\end{abstract}

Correspondence to: Professor Chun-Sheng Li or Professor Miao-Rong Xie, Department of Emergency Medicine, Beijing Friendship Hospital, Capital Medical University, 95 Yongan Road, Xicheng, Beijing 100050, P.R. China

E-mail: lcscyyy@163.com

E-mail: xiemiao27@126.com

Key words: acute pulmonary embolism, cardiac arrest, return of spontaneous circulation, angiotensin-converting enzyme, lung apoptosis of the ACE2/ACE axis is important for inhibiting pulmonary apoptosis during APE.

\section{Introduction}

Pulmonary thromboembolism is the most common cause of mortality in hospitalized patients, accounting for $\sim 60 \%$ of in-hospital mortality at present (1). A massive pulmonary embolism can lead to cardiac arrest (CA) in $41 \%$ of patients, with a mortality ranging from $65-95 \%$ (2). Pneumocyte apoptosis is the most significant pathological observation in the lung following an incidence of acute pulmonary embolism (APE). Li et al (3) have reported the presence of apoptotic cells as well as decreased expression of the anti-apoptotic proteins B-cell lymphoma (Bcl)-2 and Bcl-extra large in lung tissues following an APE, as compared with the controls. This cellular damage in the lung might be responsible for a subsequent severe lung dysfunction $(4,5)$.

The renin-angiotensin system serves an important role in the regulation of apoptosis in alveolar epithelial cells (AECs). Recently, several research groups have identified a novel pathway called angiotensin-converting enzyme2 (ACE2)-angiotensin (Ang)-1-7-Mas1 proto-oncogene, G protein-coupled receptor (Mas) axis that acts contrary to the classic ACE-Ang II-Ang II type 1 (AT1) receptor axis (6-9). The pro-apoptotic role of the classic ACE axis in AECs in response to Fas activation has been well studied (6). Ang II is known to chemically induce apoptosis in AECs (7). Wang et al (8) demonstrated that ACE2 can attenuate bleomycin-induced lung fibrosis by inhibiting the apoptosis in pulmonary epithelial cells. Similarly, Ji et al (9) demonstrated that ACE2 inhibits apoptosis in pulmonary endothelial cells during acute lung injury. Our previous study demonstrated a reduction in post-resuscitation pulmonary vascular resistance following captopril treatment, which activated the ACE2-Ang-(1-7)-Mas axis (10). However, the role of ACE2/ACE balance on pneumocyte apoptosis in massive APE-CA remains unclear. Thus, in the present study, it was aimed to examine the correlation between ACE2/ACE balance and apoptotic factors in the lung and to investigate the effect of captopril on pulmonary apoptosis in an APE-CA pig model. 


\section{Materials and methods}

Animals. As described previously (10), twenty-nine land race pigs (both sexes, aged 3 months, $28 \pm 2 \mathrm{~kg}$ ) were obtained from the Beijing Experimental Animal Center (license no. SCXK 11-00-002). All animals were housed in a cage of size $80 \times 80 \times 90 \mathrm{~cm}$ and had free access to water and standard chow. Room temperature was adjusted to $26^{\circ} \mathrm{C}$, and humidity was $60 \%$. The study procedures were approved by The Capital Medical University Institutional Animal Care Committee (permit no. 2010-D-013). Experimental protocols were designed in strict compliance with the guidelines of the Animal Care and Use Committee of Capital Medical University (Beijing, China).

Experimental preparation. All animals received an intramuscular premedication with $0.2 \mathrm{mg} / \mathrm{kg}$ midazolam followed by an ear vein injection of $1.0 \mathrm{mg} / \mathrm{kg}$ propofol. Animals were maintained under general anesthesia by a continuous administration of $3 \%$ pentobarbital $(8 \mathrm{mg} / \mathrm{kg} / \mathrm{h})$. An endotracheal tube (internal diameter $6.5 \mathrm{~mm}$ ) was fixed into trachea and a ventilator (Evita 4; Draeger Medical UK Ltd., Hertfordshire, UK) was used to assist ventilation. The ventilation mode was synchronized to a tidal volume of $8 \mathrm{ml} / \mathrm{kg}$ and a respiratory frequency of 12-20 breaths per minute on room air. An end-tidal pressure of carbon dioxide was maintained between 30 and $40 \mathrm{mmHg}$ and monitored using an infrared $\mathrm{CO}_{2}$ analyzer $\left(\mathrm{CO}_{2} \mathrm{SMO}\right.$ Plus monitor; Respironics, Inc., Murrysville, PA).

A7-F Swan-Ganz catheter (Edwards Lifesciences Corp., Irvine, CA, USA) was flowed into the pulmonary artery from the right external jugular vein to monitor mean pulmonary artery pressure. An arterial catheter was inserted into the left femoral artery to measure aortic pressure. A triple lumen central venous catheter was inserted into the left femoral vein to monitor central venous pressure. A large-bore catheter (internal diameter $1.0 \mathrm{~cm}$ ) was inserted into the left external jugular vein with its tip touching the opening of the pulmonary artery for infusion of blood clots, under the guidance of a computed tomography. Normal saline and $5 \%$ glucose saline $(8 \mathrm{ml} / \mathrm{kg} / \mathrm{h})$ were infused via the right femoral vein to compensate for the fluid loss and to maintain a constant central venous pressure (5-12 $\mathrm{mmHg}$ ). Electrocardiographic and hemodynamic parameters were also monitored (M8001A; Philips Medizin Systeme Böblingen GmbH, Böblingen, Germany).

Experimental protocol. An APE-CA model was established as described previously (10). Briefly, $100 \mathrm{ml}$ of blood was drawn out from the femoral vein and allowed to self-coagulate at room temperature $(2-3 \mathrm{~h})$. The clots $(10-15 \mathrm{ml})$ were cut into pieces $(1.5 \times 1 \times 1 \mathrm{~cm})$ and were suspended in normal saline in a large catheter tip syringe. Subsequently, the clot pieces were injected into the left external jugular vein $>2$ min until a mean arterial pressure $<30 \mathrm{mmHg}$ was reached, yielding a porcine model of APE-CA (11). To establish an APE-return of spontaneous circulation (ROSC) model, urokinase $(15,000 \mathrm{U} / \mathrm{kg})$ was infused into the pulmonary artery using a Swan-Ganz catheter and cardiopulmonary resuscitation was immediately initiated (following the 2010 American Heart Association guidelines) (12). ROSC was verified based on a systolic blood pressure $>50 \mathrm{mmHg}$ for $10 \mathrm{~min}$ (13). If ROSC was not restored within $30 \mathrm{~min}$, the animals were considered dead.

Pigs $(n=29)$ were randomly assigned into four groups. Group 1 (control group, $\mathrm{n}=5$ ) was injected with $10 \mathrm{ml}$ potassium chloride (15\%) intravenously followed by a bolus of propofol $(100 \mathrm{mg})$ at $6 \mathrm{~h}$ following experimental preparation. All animals in this group were sacrificed due to ventricular fibrillation. Group 2 (APE-CA group, $n=5$ ) underwent the procedure outlined above. All animals in this group were sacrificed due to ventricular fibrillation or electromechanical diastolic arrest. Nineteen animals received a thrombus injection as described above for the establishment of APE-ROSC model. Ten out of nineteen animals were successfully resuscitated and were randomly assigned into two subgroups: ROSC-Cap $(\mathrm{n}=5)$, receiving an injection of captopril $(22.22 \mathrm{mg} / \mathrm{kg}$; cat. no. C8856-1G, Sigma-Aldrich; Merck KGaA, Darmstadt, Germany) 30 min after ROSC, and ROSC-SA (saline; $n=5$ ), receiving an injection of equivalent normal saline $30 \mathrm{~min}$ after ROSC. Subsequently, all animals in both subgroups $(\sim 6 \mathrm{~h}$ following ROSC) were euthanized with an intravenous injection of $10 \mathrm{ml}$ potassium chloride (15\%) following a bolus of $100 \mathrm{mg}$ propofol. Lung tissue was isolated and was immediately frozen in liquid nitrogen and stored at $-80^{\circ} \mathrm{C}$ until further analysis.

Histological evaluation. Lung tissues were fixed in $10 \%$ buffered formalin for $48 \mathrm{~h}$, dehydrated with alcohol solutions of gradient concentration $(100,95,80$ and $75 \%)$, sliced at $4 \mu \mathrm{m}$ thickness, and sections were stained with hematoxylin $(15 \mathrm{sec})$-eosin $(30 \mathrm{sec})$ and dried $20 \mathrm{~min}$ at $55^{\circ} \mathrm{C}$. The lung pathological changes were observed under a light Nikon Eclipse Ci-Emicroscope (Olympus Corporation, Tokyo, Japan) under the low (10x10) and high magnification (10x40).

Western blot analysis. Each lung tissue sample (20 mg) was chopped into fragments and homogenized in $200 \mu \mathrm{l}$ radioimmunoprecipitation lysis buffer (Roche Diagnostics, Basel, Switzerland). Tissue lysates were centrifuged $(13,000 \mathrm{x} \mathrm{g}$, $20 \mathrm{~min}, 4^{\circ} \mathrm{C}$ ) and immediately harvested and stored at $-80^{\circ} \mathrm{C}$ until further use. A bicinchoninic acid protein assay kit (Pierce; Thermo Fisher Scientific, Inc., Waltham, MA, USA) was used to measure protein concentrations in the supernatant. The tissue lysate was mixed with the same volume of $5 \mathrm{X}$ sodium lauryl sulfate (SDS) buffer $[2.5 \mathrm{ml} 0.5 \mathrm{~mol} / 1$ Tris- $\mathrm{HCl}$ (pH 6.8), $0.39 \mathrm{~g}$ DTT, $0.5 \mathrm{~g}$ SDS, $0.025 \mathrm{~g}$ bromophenol blue, and $2.5 \mathrm{ml}$ glycerol] to obtain a mixture at a final concentration of $3 \mu \mathrm{g} / \mu \mathrm{l}$. The homogenates were heated at $95^{\circ} \mathrm{C}$ for $5 \mathrm{~min}$. Using 8, 10 and 15\% SDS-polyacrylamide gels, total proteins $(40 \mu \mathrm{g})$ were separated and transferred onto a $0.45-\mu \mathrm{m}$ polyvinylidene fluoride membrane (EMD Millipore, Billerica, MA, USA) for 40-100 min. Following blocking with 5\% nonfat dry milk for $1 \mathrm{~h}$ at room temperature, the membranes were incubated, first, with 1:500 dilution ofACE2 (cat. no. SC-390851), ACE (cat. no. SC-2079), AT1 receptor (cat. no. SC-81671), Bcl-2 (cat. no. SC-492) and Bcl-2-associated X protein (Bax) antibodies (cat. no. SC-6236; Santa Cruz Biotechnology, Inc., Dallas, TX, USA), 1:200 dilution of Mas receptor antibody (cat. no. AAR-013; Alomone Labs, Jerusalem, Israel), 1:1,000 dilution of cleaved caspase-3 (cat. no. 9664s; Cell Signaling Technology, Inc., Danvers, MA, USA) and caspase-3 antibodies 

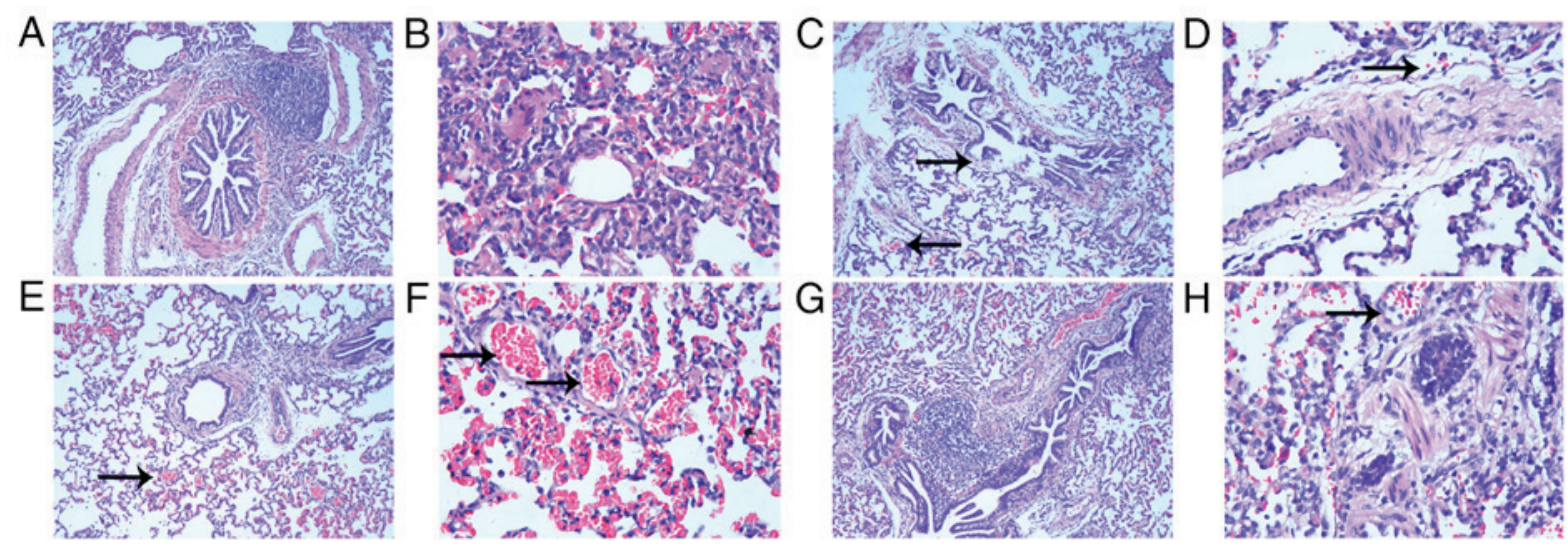

Figure 1. Histological analysis of pulmonary damage in the following experimental animal groups: Control (A) magnification, $\mathrm{x} 100$ and (B) $\mathrm{x} 400$; acute pulmonary embolism-cardiac arrest group (C) magnification, x100 and (D) x400; ROSC-saline group (E) magnification, x100 and (F) x400; and ROSC-captopril group (G) magnification, x100 and (H) x400. Black arrows indicate the alveolar space between cells. ROSC, return of spontaneous circulation.

(cat. no. SC-7272; Santa Cruz Biotechnology, Inc.), and 1:1,000 dilution of $\beta$-actin antibody (Abcam, Cambridge, UK), overnight at $4^{\circ} \mathrm{C}$, and subsequently with peroxidase-conjugated anti-rabbit or anti-mouse IgG-HRP linked secondary antibody (1:10,000 dilution; cat. no. 111-035-003; Jackson Immuno Research Laboratories, Inc., West Grove, PA, USA), for 40 min at room temperature. Bound antibodies were detected via enhanced chemiluminescence (EMD Millipore) and analyzed using a Gel Imaging System version 4.00 (Tanon Science \& Technology Co., Ltd., Shanghai. China).

Immunohistochemical staining. For the detection of cleaved caspase-3 in lung tissues, immunohistochemical staining was used. Lung tissues were fixed in $10 \%$ buffered formalin for $48 \mathrm{~h}$ at room temperature, dehydrated with alcohol solutions of gradient concentration $(100,95,80$ and $75 \%)$, sliced at $4 \mu \mathrm{m}$ thickness, and embedded in paraffin. The sections were placed in histosol for the removal of paraffin, rehydrated in graded ethanol, and blocked in 5\% bovine serum albumin (Sigma-Aldrich; Merck KGaA, Darmstadt, USA) for $4 \mathrm{~h}$. Slides were incubated with cleaved-caspase 3 antibody (1:1,000 dilution; cat. no. 9664s; CST Biological Reagents Co., Ltd., Shanghai, China) overnight at $4^{\circ} \mathrm{C}$. Sections incubated in normal rabbit serum served as negative controls. Following primary antibody incubation, sections were washed with phosphate buffer saline and were incubated with avidin-biotin peroxidase-conjugated secondary antibody (1:200; cat. no. PK-4001; ZSGB-Biotechnology; OriGene Technologies, Inc., Beijing, China) for $2 \mathrm{~h}$ at room temperature. For the development of peroxidase activity, $0.05 \%$ diaminobenzidinetetrahydrochloride (Sigma-Aldrich; Merck KGaA) was used for $10 \mathrm{~min}$ at room temperature. Sections were counterstained with hematoxylin for $20 \mathrm{sec}$ and viewed under an inverted phase microscope (IX80 microscopy; Olympus Corporation) and analyzed using Image Pro Insight 6.0 (Media Cybernetics, Inc., Rockville, MD, USA).

Electron microscopy. Within 1-2 min following isolation, lung tissues were sliced ( 1 mm thick) on ice, fixed with $2.5 \%(\mathrm{v} / \mathrm{v})$ glutaraldehyde for $30 \mathrm{~min}$ at $4^{\circ} \mathrm{C}$, postfixed with $1 \%(\mathrm{v} / \mathrm{v})$ osmic acid for $1 \mathrm{~h}$ at $4^{\circ} \mathrm{C}$, and were dehydrated and embedded with Epon 812 at $40^{\circ} \mathrm{C}$ for $4 \mathrm{~h}, 50^{\circ} \mathrm{C}$ for $2 \mathrm{~h}$, and $90^{\circ} \mathrm{C}$ for $12 \mathrm{~h}$. Thinner sections $(0.5-1 \mu \mathrm{m})$ were sliced, stained with $0.5 \%(\mathrm{w} / \mathrm{v})$ toluidine blue, and viewed under a Nikon Eclipse Ci-E microscope (Nikon Corporation, Tokyo, Japan). Ultrathin sections ( $60 \mathrm{~nm})$ were cut, double-stained with $2.0 \%(\mathrm{w} / \mathrm{v})$ uranyl acetate for $20 \mathrm{~min}$ and $2.0 \%(\mathrm{w} / \mathrm{v})$ lead citrate for $15 \mathrm{~min}$ at room temperature, and viewed under a transmission electron microscope (HITACHI HT7700; Hitachi Ltd., Tokyo, Japan).

Terminal deoxynucleotidyl transferase dUTP nick end labeling (TUNEL) assay. To obtain evidence of apoptosis in lung cells, TUNEL assay was performed according to the manufacturer's protocol (Roche Molecular Diagnostics, Pleasanton, CA, USA). Briefly, slices of lung tissues ( $4-5 \mu \mathrm{m})$ were embedded in paraffin. Cells were counted based on positive nuclei staining from five microscopic fields (magnification, x200) under a light microscope (Olympus Corporation) by an experienced pathologist. The apoptotic index of each experimental group was expressed as the ratio of the number of apoptotic cells to the total number of lung cells.

Statistical analysis. Data were expressed as the mean \pm standard deviation. Comparisons between groups were made using one-way analysis of variance with Bonferroni correction for post hoc comparison. Continuous variables were fixed to normal distribution by Kolmogorov-Smirnov test and equal variances by the homogeneity of variance test. Pearson's correlation coefficient was used to determine correlations between the ratios of ACE2/ACE, Bax, cleaved caspase-3, and Bcl-2 and the ratio of $\mathrm{Bcl}-2 / \mathrm{Bax} . \mathrm{P}<0.05$ was considered to indicate a statistically significant difference.

\section{Results}

Histological analysis of the APE-CA lung. Histological analysis of the control animals demonstrated regular bronchiolar and alveolar walls, with no congestion in the alveolus (Fig. 1A and B), whereas APE-CA animals had damaged bronchiolar and alveolar walls and mildly congestive alveolar space (Fig. 1C and D). For the ROSC-SA group, histological analysis demonstrated increased alveolar space congestion (Fig. 1E 
A
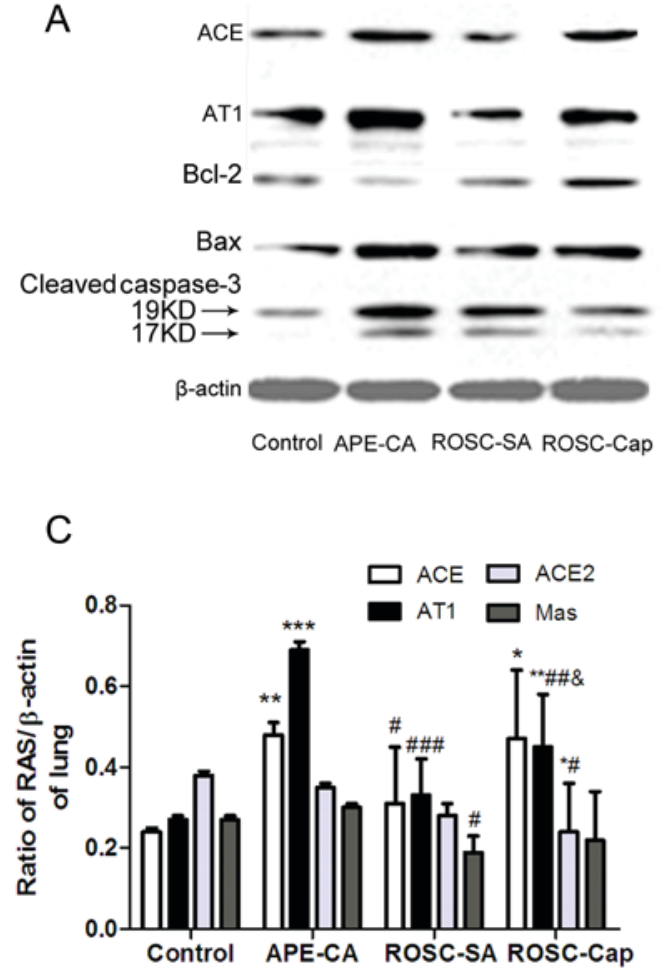

$\mathrm{B}$

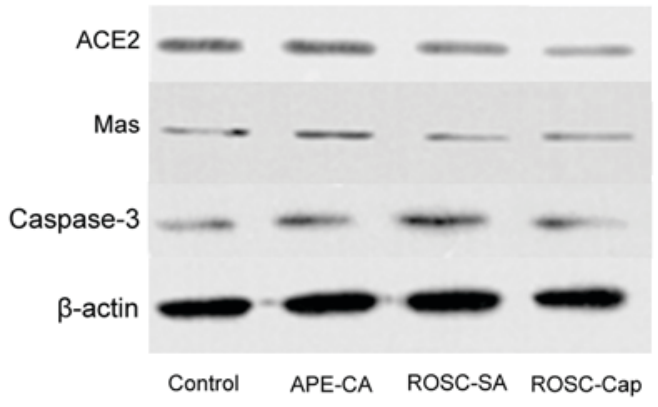

D $\quad$ B Bcl-2 $\square$ Caspase-3

Cleaved caspase-3

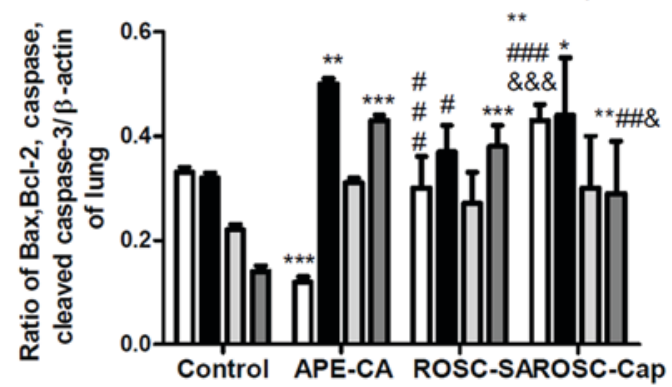

Figure 2. Representative western blots of (A) ACE, AT1, Bax, Bcl-2, cleaved caspase-3 and (B) ACE2, Mas and caspase-3, in the lung and (C) quantification of ACE2, ACE, AT1 and Mas expression levels and (D) quantification of apoptosis factors expression. Data are presented as the mean \pm standard deviation. ${ }^{*} \mathrm{P}<0.05,{ }^{* *} \mathrm{P}<0.01$ and ${ }^{* * *} \mathrm{P}<0.001$ vs. control; ${ }^{*} \mathrm{P}<0.05,{ }^{\# \#} \mathrm{P}<0.01$ and ${ }^{\# \# "} \mathrm{P}<0.001$ vs. APE-CA group; ${ }^{\&} \mathrm{P}<0.05$ and ${ }^{\text {\& \& }} \mathrm{P}<0.001$ vs. ROSC-SA group. APE, acute pulmonary embolism; CA, cardiac arrest; ROSC, return of spontaneous circulation; SA, saline; Cap, captopril; ACE, angiotensin-converting enzyme; AT1, angiotensin receptor type-1; Mas, Mas1 proto-oncogene G protein-coupled receptor. ACE, angiotensin-converting enzyme; AT1, ACE-Ang II-Ang II type1; Bcl-2, B-cell lymphoma-2; Bax, Bcl-2-associated X protein.

and F) with a large number of exudative cells and pulmonary interstitial edema. However, captopril treatment alleviated the alveolar space congestion following ROSC (Fig. 1G and H).

ACE2/ACE imbalance in the APE-CA group. The expression of ACE, AT1, ACE2, and Mas proteins in porcine lung tissues was measured by western blotting in the CA and ROSC groups following induction of APE (Fig. 2A-C). As depicted in Fig. 2C, the levels of ACE and AT1 (ACE, $0.24 \pm 0.02$ to $0.48 \pm 0.03$; AT1, $0.27 \pm 0.01$ to $0.69 \pm 0.02$ ) in the CA group were significantly higher than those of the control group $(\mathrm{P}<0.001)$, but lower in the ROSC-SA $(0.31 \pm 0.14$ and $0.33 \pm 0.09)$ compared with the CA group $(\mathrm{P}<0.05)$. The ACE2/ACE ratio declined sharply in $\mathrm{CA}$ (from $1.61 \pm 0.03$ to $0.72 \pm 0.04$ ) following induction of APE. Notably, the protein levels of Mas receptor were decreased in the ROSC-SA group following induction of APE $(0.19 \pm 0.04)$

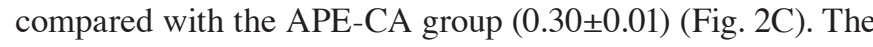
expression of AT1 receptor increased, but ACE2 and Mas receptor expression levels were unchanged in the ROSC-Cap compared with the ROSC-SA group.

Ultrastructural changes in lung cells. Pulmonary endothelial cell apoptosis and endothelial matrix proliferation in the APE-CA and ROSC-SA groups are illustrated in Fig. 3A and B. Electron microscopy demonstrated loose connections between endothelial cells, extensive nuclear shrinkage, chromatin condensation and margination, cytoplasmic vacuoles (Fig. 3C), as well as type II pneumocyte with lamellar body swelling and partial desquamation, in the APE-CA group (Fig. 3D).
Pulmonary apoptosis and the effect of captopril on the APE-CA group. To measure pulmonary apoptosis, the expression of Bax, Bcl-2, cleaved caspase-3 (Fig.2A) and caspase-3 (Fig.2B) proteins in the lung tissues was evaluated by western blot analysis. The pro-apoptotic protein Bax was higher in the pulmonary tissue of the APE-CA and ROSC-SA groups following induction of APE compared with the control group ( $\mathrm{P}<0.05$; Fig. 2D). However, Bax protein levels were lower in the ROSC-SA group than in the APE-CA group $(\mathrm{P}<0.05)$. Compared with the control group, although the expression of anti-apoptotic protein Bcl-2 (and the $\mathrm{Bcl}-2 / \mathrm{Bax}$ ratio) were lower in the APE-CA group $(\mathrm{P}<0.001)$, these returned to normal levels during ROSC following APE. Cleaved caspase- 3 or cleaved caspase-3/caspase-3 ratio was upregulated in the CA and ROSC-SA groups compared with the control group ( $\mathrm{P}<0.001$; Fig. 2D). Captopril treatment inhibited pulmonary cleaved caspase- 3 expression and promoted Bcl-2 expression compared with the saline administration following ROSC (Fig. 2A, D). The expression of cleaved caspase-3 was analyzed by conventional immunohistochemistry. Cleaved caspase-3 expression was not detected in the control group (Fig. 4A) but was markedly observable in the nucleus and cytoplasm of pulmonary epithelial cells of the APE-CA and ROSC groups (Fig. 4B-E). Additionally, captopril reduced cleaved caspase-3 staining in lung epithelial cells following ROSC (Fig. 4D and E). Furthermore, based on the results of TUNEL assay, the apoptotic index in APE-CA and ROSC-SA groups increased compared with the control group, and after ROSC, captopril treatment partially attenuated pulmonary apoptotic index (Fig. 5). 

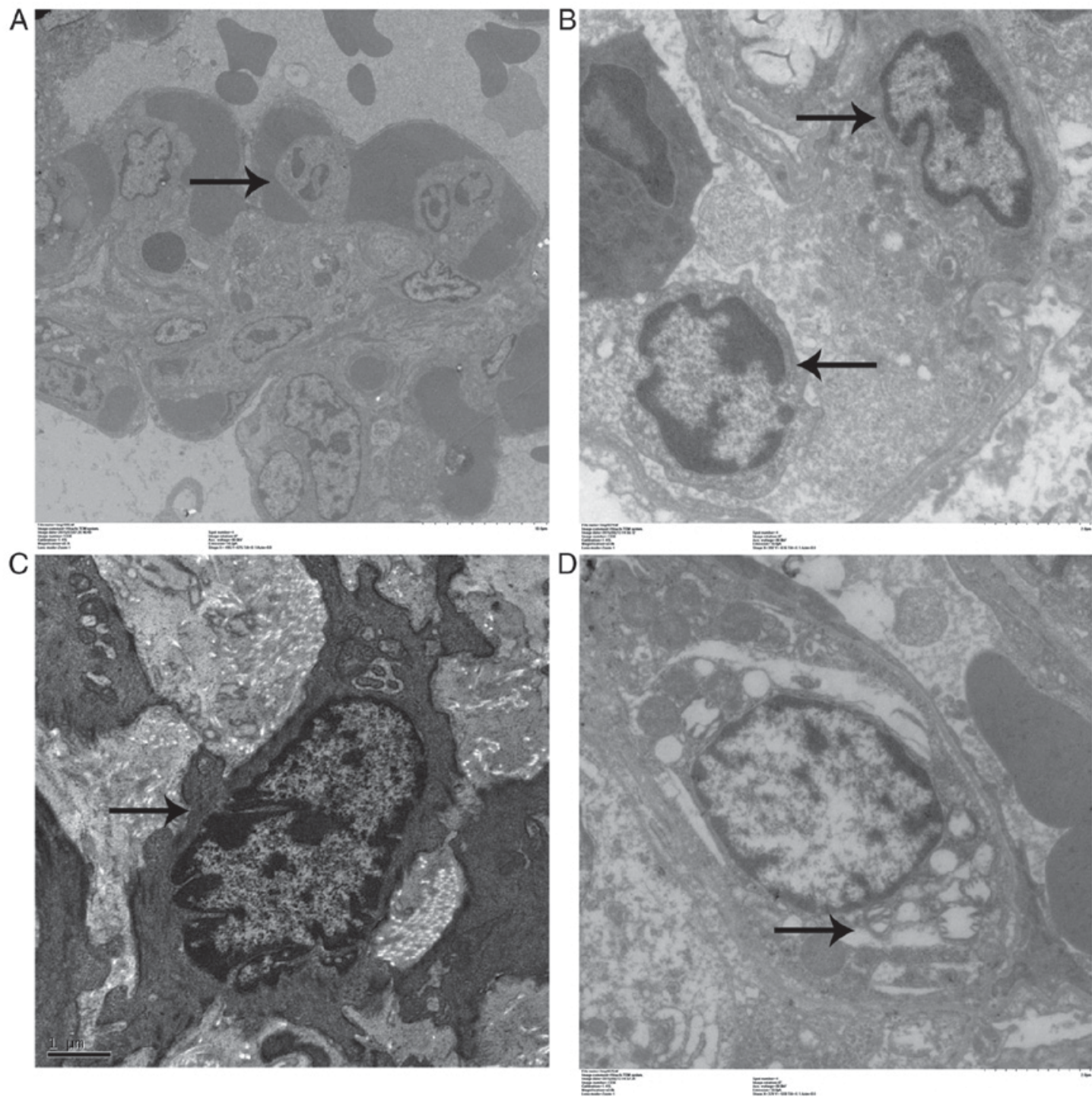

Figure 3. Ultrastructure representative images of pulmonary epithelial cells depicting apoptosis, in (A) acute pulmonary embolism-cardiac arrest (80 kV x7,000), (B) return of spontaneous circulation-saline group $(80 \mathrm{kV}$ x30,000), (C) epithelial cells $(80 \mathrm{kV}$ x 100,000) and (D) type II pneumocytes with lamellar body desquamation $(80 \mathrm{kV} \times 30,000)$ in the APE-CA group. Black arrows indicate apoptotic cells.

Correlation between ACE2/ACE and apoptotic factors during an $A P E$. A negative correlation between ACE2/ACE ratio and $\mathrm{Bax}(\mathrm{r}=-0.772, \mathrm{P}<0.01)$ was detected. The protein levels between ACE2/ACE ratio and cleaved caspase- 3 were negative correlative factors $(\mathrm{r}=-0.689, \mathrm{P}<0.05)$ and the $\mathrm{Bcl}-2(\mathrm{r}=0.559$, $\mathrm{P}<0.05)$ and $\mathrm{Bcl}-2 / \mathrm{Bax}$ ratio $(\mathrm{r}=0.716, \mathrm{P}<0.01)$ were positive correlative factors of ACE2/ACE ratio (Fig. 6).

\section{Discussion}

Pneumocyte apoptosis is the most significant pathological observation in the lung tissue following an APE. The association between ACE2/ACE axis and the pathological changes in the lung during ischemia and reperfusion induced by massive APE has not been established. The present study aimed to investigate this association by inducing CA (ischemia) and ROSC (reperfusion) in an APE pig model. The present study observed congested alveolar space and apoptosis in endothelial cells, which may be due to the loss of ACE2/ACE balance in the lung tissue and reduced ACE2/ACE ratio. The apoptosis in lung tissue was aggravated at the APE-CA group, but was attenuated following ROSC. Following captopril treatment, apoptosis in the lung tissue was alleviated. Thus, it can be concluded that the ACE2/ACE balance may be positively correlated with the expression of anti-apoptotic factors during APE-induced lung injury in the pig model.

Apoptosis is the main mechanism of histological pulmonary injury in APE-CA (3). Deng et al (14) established a canine model of pulmonary thromboembolism by selectively embolizing blood clots to the right lower lobar pulmonary artery. After 2 weeks, embolectomy of the reperfusion and ischemia groups revealed similar pulmonary pathology to the present study, including collapsed alveolar structures and the presence of few exudative cells in the alveolar space in the ischemia group (comparable to the APE-CA group) and a large number of exudative cells and exudation within the alveolar spaces in the reperfusion group (comparable to the ROSC groups). In the present study, higher congestion in the alveolar spaces was present in the ROSC group compared with the APE-CA group. However, captopril treatment inhibited alveolar congestion. 

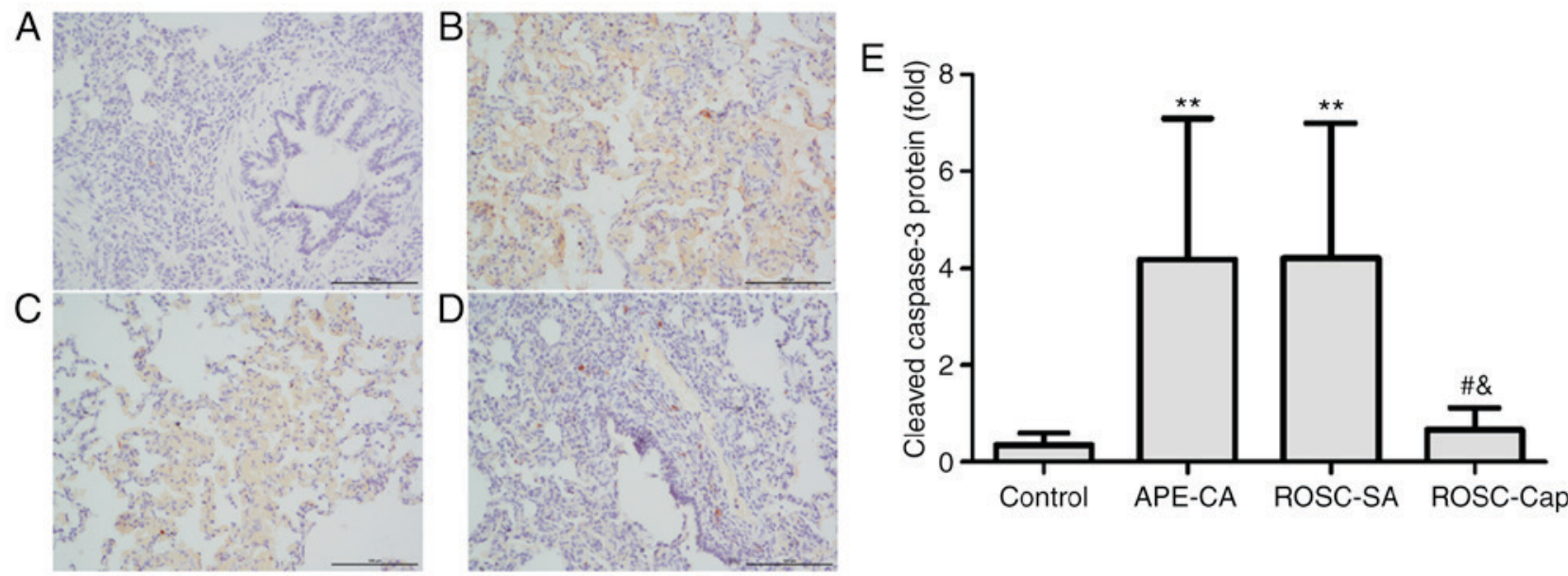

Figure 4. Representative images of cleaved caspase-3 in the (A) control, (B) APE-CA, (C) ROSC-SA and (D) ROSC-Cap groups and (E) quantification of its expression levels, as assessed by immunohistochemical staining. Data are presented as the mean \pm standard deviation. ${ }^{* *} \mathrm{P}<0.01 \mathrm{vs}$. control; ${ }^{*} \mathrm{P}<0.05 \mathrm{vs}$. APE-CA; ${ }^{\&} \mathrm{P}<0.05$ vs. ROSC-SA group. Scale bar, $100 \mu \mathrm{m}$. Brown staining indicates positive expression of cleaved caspase-3. APE, acute pulmonary embolism; CA, cardiac arrest; ROSC, spontaneous circulation; SA, saline; Cap, captopril.
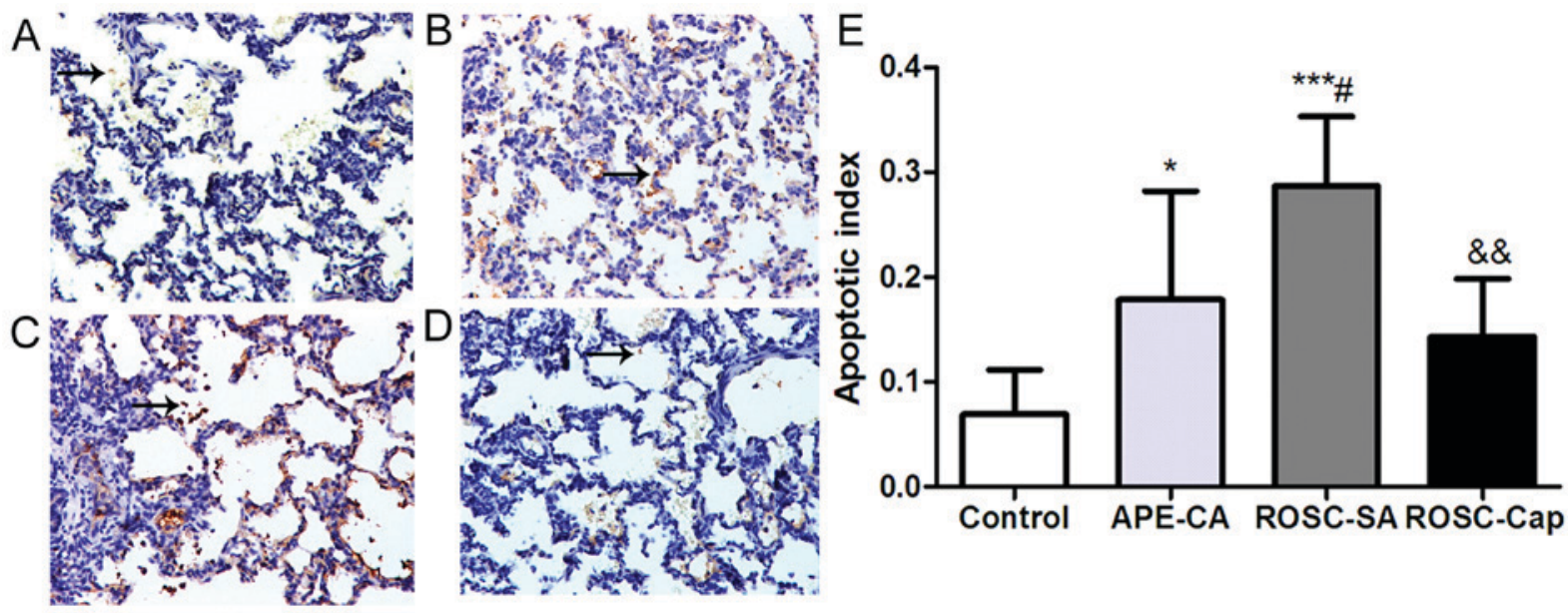

Figure 5. TUNEL assay of pulmonary apoptosis in the (A) Control and (B) APE-CA and (C) ROSC-SA and (D) ROSC-Cap groups and (E) quantification of their apoptotic index. Data are presented as the mean \pm standard deviation. ${ }^{*} \mathrm{P}<0.05$ vs. control; ${ }^{* * * *} \mathrm{P}<0.001$ vs. control; ${ }^{*} \mathrm{P}<0.05$ vs. APE-CA group; ${ }^{\&} \& \mathrm{P}<0.01$ vs. ROSC-SA group. Scale bar is $100 \mu \mathrm{m}$. Black arrows indicate TUNEL-positive nuclei. TUNEL, terminal deoxynucleotidyl transferase dUTP nick end labeling; ROSC, spontaneous circulation; SA, saline; Cap, captopril.

Electron microscopy visualization revealed apoptosis in pulmonary endothelial cells and type II pneumocytes with lamellar bodies partially desquamated in the APE-CA model. Thus, alveolar congestion may have been caused by injury to the alveolar epithelial barriers resulting from pulmonary endothelial cell apoptosis.

The role of apoptosis in the pathogenesis of interstitial pulmonary fibrosis, acute respiratory distress syndrome, and chronic obstructive pulmonary disease has been described previously (15-18). Recent studies suggested that apoptosis serves an important role in chronic pulmonary embolism (19-22). In a mouse model of chronic pulmonary thromboembolism, lung parenchyma had markedly elevated levels of proliferating cells and apoptotic cells, and activity of pro-apoptotic caspase-3 compared with normal lungs (19). Mercier et al (20) investigated vessel alterations induced by high flow through the creation of an aortopulmonary shunt and reported increased smooth muscle cell proliferation, but following 1 week of shunt closure, smooth muscle cells demonstrated increased apoptosis without proliferation. Dolkart et al (21) reported that the rate of apoptosis in the bronchoalveolar lavage peaks at 12 and $48 \mathrm{~h}$ following ischemia-reperfusion. When investigating the mechanisms associated with lung ischemia-reperfusion injury in pulmonary thromboembolism, Deng et al (22) demonstrated that the number of apoptotic pneumocytes had a negative correlation with the ratio of arterial oxygen partial pressure to fractional inspired oxygen, whereas it had a positive correlation with alveolar polymorphonuclear neutrophils in the reperfusion group. In the present study, APE-CA and ROSC groups had increased levels of the pro-apoptotic factors Bax and cleaved caspase-3, and inhibition of the anti-apoptotic factor Bcl-2 compared with the control group. Following ROSC, the reperfusion may have alleviated apoptosis in the lung cells as indicated by the reduction in Bax and the increase of Bcl-2 expression compared with the APE-CA group. 


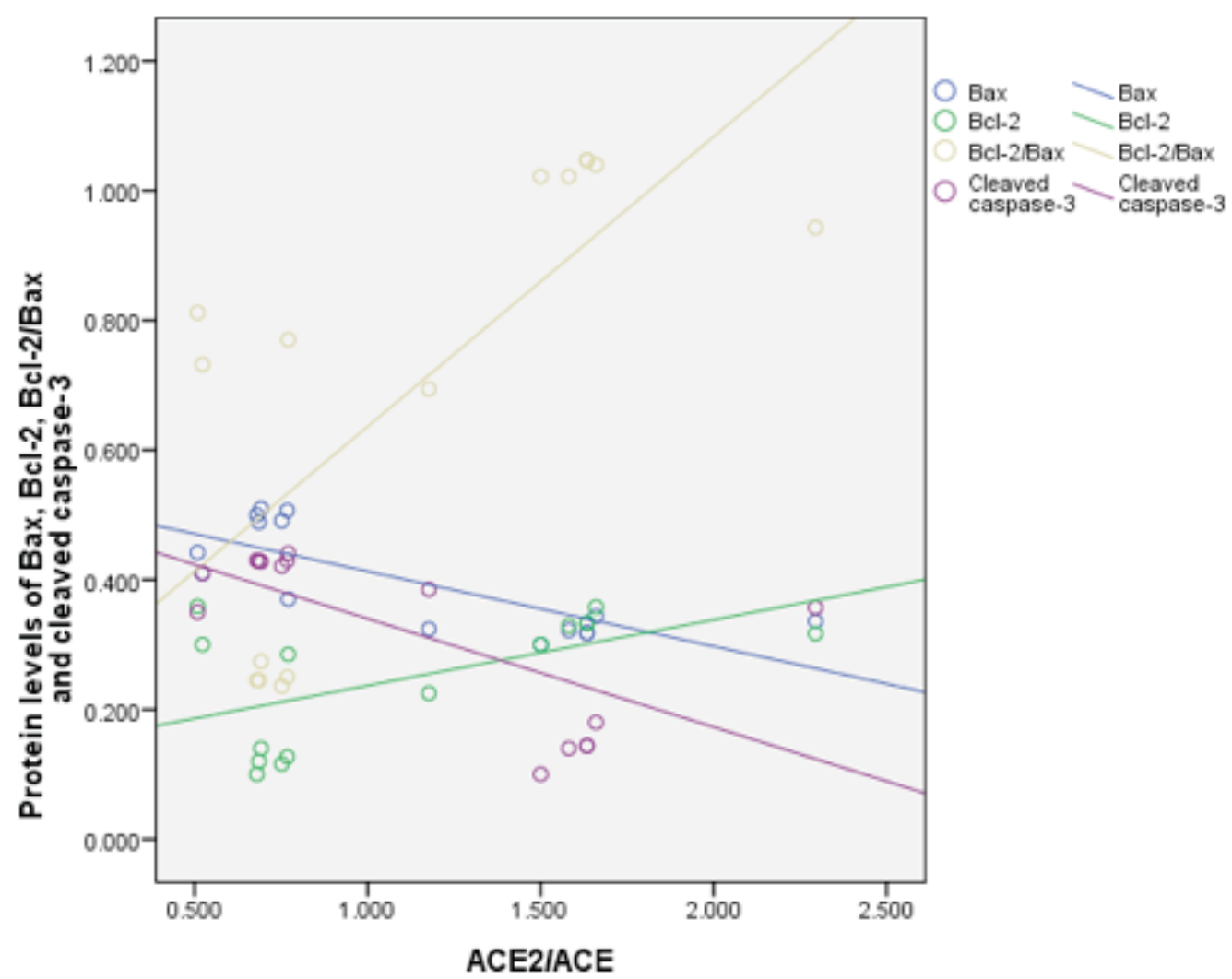

Figure 6. Correlation between protein levels of ACE2/ACE and apoptotic factors during an APE. ACE, angiotensin-converting enzyme; Bcl-2, B-cell lymphoma-2; Bax, Bcl-2-associated X protein.

Previous studies have reported that the classical ACE-AngII-AT1 axis of the renin-Ang system serves an important role in the apoptosis of AECs induced by either Fas activation, or chemically by antiarrhythmic agents benzofuran amiodarone (6) or fibrogenic agent bleomycin (7). A study reported that an AT1 receptor blocker, losartan, reduced the protein levels of caspase-3 in lipopolysaccharide (LPS)-induced lung injury (23). Additionally, evidence of inhibition of pneumocyte apoptosis via activation of ACE2/Ang-(1-7)/Mas axis has been reported. Yang et al (24) proved that Ang-(1-7) treatment is effective in ameliorating Ang II-induced apoptosis in human umbilical vein endothelial cells. Li et al (25) illustrated that LPS induced apoptosis in pulmonary microvascular endothelial cells and reduced the ratio of ACE2/ACE, while ACE2 treatment alleviated LPS-induced apoptosis by reversing the ACE2/ACE imbalance and increasing Ang-(1-7) levels. Other studies have demonstrated that the ACE2/ACE imbalance is an important pathological mechanism not only in LPS-induced acute lung injury but also in many diseases such as in spontaneous hypertension (26), acute pancreatitis (27,28), hepatic fibrogenesis (29), and in renal injury (30). In agreement with these studies, the present reported that there was a positive correlation between ACE2/ACE ratio and anti-apoptotic factors in APE-CA pigs, suggesting that restoring the ACE2/ACE balance may be a therapeutic strategy for resolving pneumonocyte apoptosis.

Captopril treatment has been widely investigated in several studies on pulmonary and cardiac diseases. Fan et al (31) demonstrated that captopril treatment resulted in lower expression of ACE and AT1 receptors and higher expression of ACE2 and AT2 receptors in mouse Lewis lung carcinoma cells under hypoxia conditions. Li et al (32) in an in vivo study using rat pulmonary microvascular endothelial cells demonstrated that captopril pretreatment significantly reversed the LPS-induced pathophysiological changes in the lung, reduced the ratio of Ang II to Ang-(1-7), and restored the ACE/ACE2 ratio to normal levels. Our previous study demonstrated that captopril treatment lowered post-resuscitation pulmonary vascular resistance in pulmonary embolism by activating the serum ACE2/Ang-(1-7)/Mas axis (10). In the present study, the anti-apoptotic action of captopril in lung epithelial cells following ROSC was demonstrated by increased Bcl-2 protein levels, as assessed by western blot analysis and decreased cleaved caspase-3 protein levels, as assessed by immunohistochemical analysis. In addition, the TUNEL assay showed that the apoptotic index was decreased following captopril treatment.

However, the present study has some limitations. Firstly, although the porcine model is expected to simulate the human model of APE-CA injury, the results may be hindered by species and organ-dependent differences. Additionally, the present experiments did not measure lung injury biomarkers in parallel, and thus the correlation between ACE2/ACE axis and lung injury could not be validated. Therefore, the molecular signaling pathway(s) mediating the effects of the ACE2 axis on post-resuscitation lung apoptosis in APE require further investigation.

In conclusion, the present study confirmed that a loss of ACE2/ACE balance may be a key mechanism of pathogenesis in APE-CA. Levels of apoptotic proteins were elevated in APE-CA animals, but this effect was reversed following ROSC. Treatment with captopril had anti-apoptotic effects in the lung tissue following ROSC. Taken together, 
the present study indicated that restoring the ACE/ACE2 balance may be an important therapeutic strategy in the management of APE-CA.

\section{Acknowledgements}

The present study was supported by the National Natural Science Foundation of China (grant no. 81372025), the 2015 Annual Special Cultivation and Development Project for Technology Innovation Base of Beijing Key Laboratory of Cardiopulmonary Cerebral Resuscitation (grant no. Z151100001615056) and the Beijing Natural Science Foundation (grant no. 7173253).

\section{References}

1. Chesnutt MS, Prendergast TJ, McPhee SJ, Papadakis MA and Tierney LM Jr: Pulmonary venous thromboembolism. In: Current Medical Diagnosis and Treatment. 46th edition. New York McGraw Hill 28: 284-294, 2007.

2. Kuisma M and Alaspää A: Out-of-hospital cardiac arrests of non-cardiac origin. Epidemiology and outcome. Eur Heart J 18: $1122-1128,1997$.

3. Li SQ, Jian W, Liu AR, Zhao F, Ti XY and Ouyang HF: Expression of apoptosis related protein in transforming growth factors-beta signaling pathway and its effects on the cell apoptosis in the lung tissues after acute pulmonary embolism. Zhongguo Wei Zhong Bing Ji Jiu Yi Xue 20: 353-356, 2008 (In Chinese).

4. Fischer S, Cassivi SD, Xavier AM, Cardella JA, Cutz E, Xavier AM, Edwards V, Liu M and Keshavjee S: Cell death in human lung transplantation: Apoptosis induction in human lungs during ischemia and after transplantation. Ann Surg 231: 424-431, 2000.

5. Van Putte BP, Kesecioglu J, Hendriks JM, Persy VP, van Marck E, van Schil P and Broe ME: Cellular infiltrates and injury evaluation in a rat model of warm pulmonary ischemia-reperfusion. Crit Care 9: R1-R8, 2005.

6. Bargout R, Jankov A, Dincer E, Ibarra-Sunga O, Komodromos T, Filippatos G and Uhal BD: Amiodarone induces apoptosis in human and rat alveolar epithelial cells in vitro Am J Physiol Lung Cell MolPhysiol 278: L1039-L1044, 2000.

7. Wang R, Ibarra-Sunga O, Verlinski L, Pick R and Uhal BD: Abrogation of bleomycin-induced epithelial apoptosis and lung fibrosis by captopril or by a caspase inhibitor. Am J Physiol Lung Cell MolPhysiol 279: L143-L151, 2000.

8. WangL, Wang Y,Yang T, Guo YandSunT:Angiotensin-Converting Enzyme 2 attenuates Bleomycin-induced lung fibrosis in mice. Cell Physiol Biochem 36: 697-711, 2015.

9. Ji Y, Gao F, Sun B, Hao J and Liu Z: Angiotensin-converting enzyme 2 inhibits apoptosis of pulmonary endothelial cells during acute lung injury through suppressing SMAD2 phosphorylation. Cell Physiol Biochem 35: 2203-2212, 2015.

10. Xiao HL, Li CS, Zhao LX, Yang J, Tong N, An L and Liu QT: Captopril improves postresuscitation hemodynamics protective against pulmonary embolism by activating the ACE2/Ang-(1-7)/Mas axis. Naunyn Schmiedebergs Arch Pharmacol 389: 1159-1169, 2016.

11. Pantazopoulos IN, Xanthos TT, Vlachos I, Troupis G, Kotsiomitis E, Johnson E, Papalois A and Skandalakis P: Use of the impedance threshold device improves survival rate and neurological outcome in a swine model of asphyxial cardiac arrest. Crit Care Med 40: 861-868, 2012.

12. Travers AH, Rea TD, Bobrow BJ, Edelson DP, Berg RA, Sayre MR, Berg MD, Chameides L, O'Connor RE and Swor RA: Part 4: CPR overview: 2010 American heart association guidelines for cardiopulmonary resuscitation and emergency cardiovascular care. Circulation 122 (18 Suppl 3): S676-S684, 2010.

13. Stadlbauer KH, Rheinberger K, Wenzel V, Raedler C, Krismer AC, Strohmenger HU, Augenstein S, Wagner-Berger HG, Voelckel WG, Lindner KH and Amann A: The effects of nifedipine on ventricular fibrillation mean frequency in a porcine model of prolonged cardiopulmonary resuscitation. Anesth Analg 97: 226-230, 2003.

14. Deng C, Yang M, Lin Q, Yang Y, Zhai Z, Liu K, Ding H, Cao X, Huang Z, Zhang L and Zhao J: Beneficial effects of inhaled NO on apoptotic pneumocytes in pulmonary thromboembolism model. Theor Biol Med Model 11: 36, 2014.
15. Hagimoto N, Kuwano K, Miyazaki H, Kunitake R, Fujita M, Kawasaki M, Kanika Y and Hara N: Induction of apoptosis and pulmonary fibrosis in mice in response to ligation of FAS antigen. Am J Respir Cell MolBiol 17: 272-278, 1997.

16. Kuwano K, Kunitake R, Kawasaki M, Nomoto Y, Hagimoto N, Nakanishi Y and Hara N: P21Waf1/Cip1/Sdi1 and p53 expression in association with DNA strand breaks in idiopathic pulmonary fibrosis. Am J Respir Crit Care Med 154: 477-483, 1996.

17. Matute-Bello G, Liles WC, Steinberg KP, Kiener PA, Mongovin S, Chi EY, Jonas M and Martin TR: Soluble Fas ligand induces epithelial cell apoptosis in humans with acute lung injury (ARDS). J Immunol 163: 2217-2225, 1999.

18. Segura-Valdez L, Pardo A, Gaxiola M, Uhal BD, Becerril C and Selman M: Upregulation of gelatinases A and B, collagenases 1 and 2, and increased parenchymal cell death in COPD. Chest 117: 684-694, 2000.

19. Wagner EM, Petrache I, Schofield B and Mitzner W: Pulmonary ischemia induces lung remodeling and angiogenesis. J Appl Physiol (1985) 100: 587-593, 2006.

20. Mercier O, Sage E, de Perrot M, Tu L, Marcos E, Decante B, Baudet B, Hervé P, Dartevelle P, Eddahibi S and Fadel E: Regression of flow-induced pulmonary arterial vasculopathy after flow correction in piglets. J Thorac Cardiovasc Surg 137: 1538-1546, 2009.

21. Dolkart O, E A, S S, S M, P G and Aa W: Temporal determination of lung NO system and COX-2 upregulation following ischemia-reperfusion injury. Exp Lung Res 40: 22-29, 2014.

22. Deng C, Zhai Z, Wu D, Lin Q, Yang Y, Yang M, Ding H, Cao X, Zhang $Q$ and Wang C: Inflammatory response and pneumocyte apoptosis during lung ischemia-reperfusion injury in an experimental pulmonary thromboembolism model. J Thromb Thrombolysis 40: 42-53, 2015.

23. Deng W, Deng Y, Deng J, Wang DX and Zhang T: Losartan attenuated lipopolysaccharide-induced lung injury by suppression of lectin-like oxidized low-density lipoprotein receptor-1. Int J Clin Exp Pathol 8: 15670-15676, 2015.

24. Yang HY, Bian YF, Zhang HP, Gao F, Xiao CS, Liang B, Li J, Zhang NN and Yang ZM: Angiotensin-(1-7) treatment ameliorates angiotensin II-induced apoptosis of human umbilical vein endothelial cells. Clin Exp Pharmacol Physiol 39: 1004-1010, 2012.

25. Li Y, Cao Y, Zeng Z, Liang M, Xue Y, Xi C, Zhou M and Jiang W: Angiotensin-converting enzyme 2/angiotensin-(1-7)/Mas axis prevents lipopolysaccharide-induced apoptosis of pulmonary microvascular endothelial cells by inhibiting $J N K / N F-\kappa B$ pathways. Sci Rep 5: 8209, 2015.

26. Gowrisankar YV and Clark MA: Angiotensin II regulation of angiotensin-converting enzymes in spontaneously hypertensive rat primary astrocyte cultures. J Neurochem 138: 74-85, 2016.

27. Gaddam RR, Ang AD, Badiei A, Chambers ST and Bhatia M: Alteration of the renin-angiotensin system in caerulein induced acute pancreatitis in the mouse. Pancreatology 15: 647-653, 2015.

28. Liu R, Qi H, Wang J, Wang Y, Cui L, Wen Y and Yin C: Angiotensin-converting enzyme (ACE and ACE2) imbalance correlates with the severity of cerulein-induced acute pancreatitis in mice. Exp Physiol 99: 651-663, 2014.

29. Moreira de Macêdo S, Guimarães TA, Feltenberger JD and Sousa Santos SH: The role of renin-angiotensin system modulation on treatment and prevention of liver diseases. Peptides 62: 189-196, 2014.

30. Yang XH, Wang YH, Wang JJ, Liu YC, Deng W, Qin C, Gao JL and Zhang LY: Role of angiotensin-converting enzyme (ACE and ACE2) imbalance on tourniquet-induced remote kidney injury in a mouse hindlimb ischemia-reperfusion model. Peptides 36: 60-70, 2012.

31. Fan L, Feng Y, Wan HY, Ni L, Qian YR, Guo Y, Xiang Y and Li QY: Hypoxia induces dysregulation of local renin-angiotensin system in mouse Lewis lung carcinoma cells. Genet Mol Res 13: 10562-10573, 2014

32. Li Y, Zeng Z, Li Y, Huang W, Zhou M, Zhang X and Jiang W: Angiotensin-converting enzyme inhibition attenuates lipopolysaccharide-induced lung injury by regulating the balance between angiotensin-converting enzyme and angiotensin-converting enzyme 2 and inhibiting mitogen-activated protein kinase activation. Shock 43: 395-404, 2015.

This work is licensed under a Creative Commons Attribution-NonCommercial-NoDerivatives 4.0 International (CC BY-NC-ND 4.0) License. 